\title{
Social Communication and Modern Opinion Leaders - Youtube Bloggers
}

\author{
Marina Terskikh \\ Faculty of Philology and Media Communication, Chair of General and Applied Linguistics, Dostoevsky Omsk State University, Omsk, \\ Russia
}

\begin{abstract}
Today, video blogging became the trend of modern Internet-communication that attracts the younger audiences due to its openness and availability compared to traditional mass media. Many companies engage bloggers in the process of commercial product promotion, less often they take part in social project management. Practice shows that involvement of YouTube bloggers in the process of social projects' creation and promotion is one of the most effective ways to influence the target audience. On the other hand, social communication with bloggers as opinion leaders - involved has not been researched; there are no publications on this issue. This fact stipulates the necessity to research and describe the usage of bloggers' reputation capital in the process of social communications aimed at fighting modern social issues.
\end{abstract}

\section{Introduction}

Every year, communication tools used to attract the audiences of commercial and social advertising are becoming more and more elaborate; thanks to, among other things, the brisk development of modern media technologies. This quick renewal of communication tools and channels can be explained by the audience being surfeited with definite types of advertising, as well as by "media ageing" - the ageing of communication tools against the background of technical progress - when the stereotypic advertisements are superseded by more interesting and unconventional ones [1-5].

Due to its powerful emotional element social advertising becomes one of the most manipulative types of advertising; on the other hand, it exists under the conditions of a tough competitive struggle. The recipient of an advertising message becomes more demanding in terms of quality and creative potential of social communications. That is why the designers of social projects are always in search of new methods to attract the recipients' attention. Development of the Internet technologies is responsible for the creation of new communication channels, such as social networks, video hosting services, blogging platforms, microblogs, etc. Each of these channels has its "stars" whose audiences can be compared to the ones of non-Internet celebrities.

One of such relatively new channels of social communication discourse is communicative activities using modern content-makers. There are not many social campaigns of this sort, although the results of social projects implemented allow us to consider the involvement of YouTube bloggers as an effective tool of influencing the recipients and promoting social values, especially in the case of young audiences.

The key task of social advertising is to appeal to the public. This type of communication is used to promote a certain life model. Bloggers, being modern opinion leaders, make the message of social advertisement more understandable and accessible to the target audience of this social communication.

\section{Bloggers' reputation capital and its use in social projects management}

Video blogging has recently invaded the Internet. The newsfeed of social networks is full of popular people - opinion leaders - those who were unknown to the public just a short time ago. Every year there are more and more research works dedicated to the problems of video blogging as an advertising and PRtool [6-8]. Just a few years ago, it was impossible to hear of YouTube bloggers from TV screens; now famous video bloggers are frequent visitors to the most popular channels. It is connected with the fact that TV is starting to lose its audience, especially the youngsters. In search for free content, the young viewer often browses the Internet, especially YouTube, where they can find all necessary information in a convenient form.

Let us have a look at how the reputation capital of some famous YouTube bloggers is used in different social campaigns.

\footnotetext{
Corresponding author: terskihm@mail.ru
} 
One of the companies that work with its audiences quite actively is Google. It attracts to its social projects not only famous Russian athletes and actors but also popular bloggers.

For example in 2014, Google implemented a project "Karenina. Live Edition" together with the Yasnaya Polyana Memorial Estate. For two days, Google+ was broadcasting 723 people from 34 places who have been reading one of the most prominent books of the world literature, Leo Tolstoy's Anna Karenina.

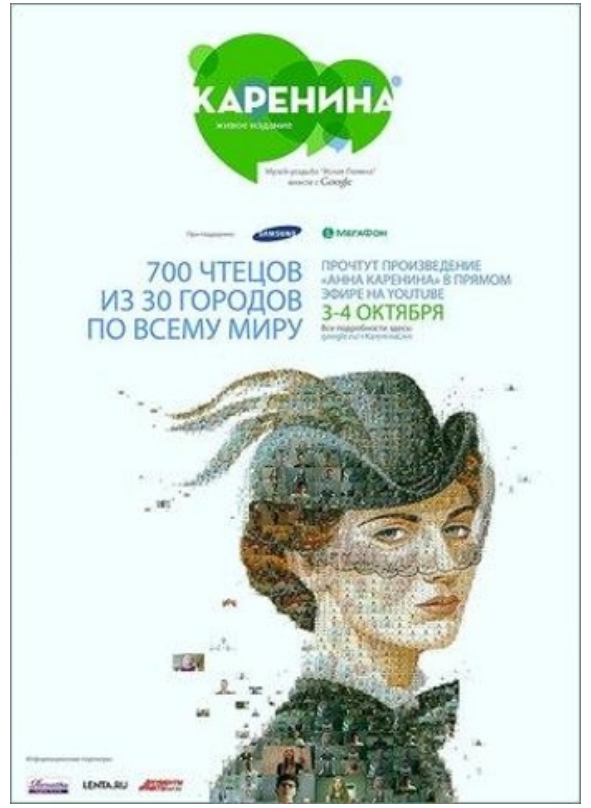

Among the readers who broadcasted live from around the world, there were popular Russian bloggers: stand-up comedian and blogger Danila Poperechny, beauty-blogger Maria Way, bloggers Sasha Spielberg, Kostya Pavlov, and Max Brandt.

One of the aims of this social project was to popularize culture and reading being its part, to unite people all around the world by means of reading Russian classic literature.

To advertise its online project Google created a video called "Fall in love again. Karenina. Live Edition" and uploaded to its official YouTube channel; in this video celebrities were telling about a social online project, which was about to start.

"I want to become something more than myself (Andrey Vorontsevich, the forward of CSKA basketball club, a member of Russian National Team). I want to immerse myself in the world of pure taste (Maria Way, YouTube beauty-blogger). I want everyone to feel the power of the word (in signlanguage) (Nikolay Reutov, designer). I want to show what woman can do (Adelina Sotnikova, Russian figure-skater, the first Olympic champion in singles figure skating). I want to show that the great novel of my great grandfather unites people all over the world. That is why we are creating a new version of Anna Karenina narrated live by hundreds of people using state-of-the-art Internet technologies. Join our project; go to the project webpage at Google+ (Fyokla Tolstaya, journalist, the project's curator)".
Each phrase said by the celebrities in this video starts with the words "I want". This repetition tool is one of persuasion tools that are frequently used in advertising discourse; it allows introducing necessary stereotypes into the recipient's consciousness by turning this repeated thought into a statement which minimizes all speculations. A person starts believing this statement and performing all actions necessary for the manipulator subconsciously.

On the other hand, all statements in this video correlate with the speakers' personal or physical characteristics: basketball player Andrey Vorontsevich makes a comparison to his height, numb designer Nikolay Reutov is talking about the power of word using sign-language, Olympic champion in women singles ice-skating makes a reference to her triumph in Sochi and mentions Russian woman's strengths.

In 2015, Google together with Chekov's Moscow Art Theatre organized one more literature social project - Chekov is Alive - dedicated to the contribution Anton Chekov made to the world literature. In the frameworks of these projects, both celebrities and ordinary people were reading Chekov's stories live on YouTube.

To advertise this online project Google created a video starting with a question "What Chekov's character are you?"

"I am Baron Tuzenbach from Three Sisters, the ultimate dreamer (Timur Rodrigez, a singer and a showman). I am Ariadna, a predator (Renata Litvinova, an actress and a director). Petya Trofimov from The Cherry Orchard, a perpetual student (Andrey Burkovsky, an actor). I am Jenya from The House with the Mezzanine, a bride (Nyusha, a singer and a composer). I am Ragin from Ward No. 6, a defeated one (Ilya Glinnikov, an actor). Anna Sergeyevna from the Lady with the Dog, a pretty sinner (Byanka, a singer). I am Katya from A Boring Story (Kate Clapp, a videoblogger). I am Belikov from The Man in the Case (L'One, a rap-singer). I am Treplev from The Seagull, a wanderer (Igor Vernik, an actor).

Do the quiz and find out which Chekov's character you are. Take part in the casting and join us in online readings.

In this advertising video, each of the characters has his or her own type, which is defined by verbal and non-verbal elements. Each phrase is started with the pronoun I; it means that each cast member impersonates one of Chekov's characters.

This text also uses imperatives. For example, an interrogative-hortative construct "Which Chekov's character are you?" or a verb in an imperative form marking the speaker's attempt to make somebody do something: "do the quiz", "take part", “join". All these tools form an illocutionary act.

As for non-verbal elements of the video, each of the cast members had his or her own part reflected in the locations, make-up, prompts, gestures, mimic, etc. For example, an actor playing the character from Ward No. 6 was wearing a straitjacket; on the other hand, singer Nyusha was wearing a wedding dress. 
Compared to "Karenina. Live Edition" campaign, "Chekov is Alive" project involved much more bloggers, some of them being top ones and having more than a million of followers on YouTube, for example, Kate Clapp, Ruslan Usachev, Valerya Lyubarskaya, Eldar Jakharov, Maria Novosad, Mikhail Kshishtovsky, etc.

Talking about locations it should be noted that most of them were recorded in the areas defined on the social project's website. Although recording of the story The Black Monk read by a top blogger Kate Clapp was an exception because she was reading her extract at "Chekovskaya" Metro station; this location added some entourage to this video.

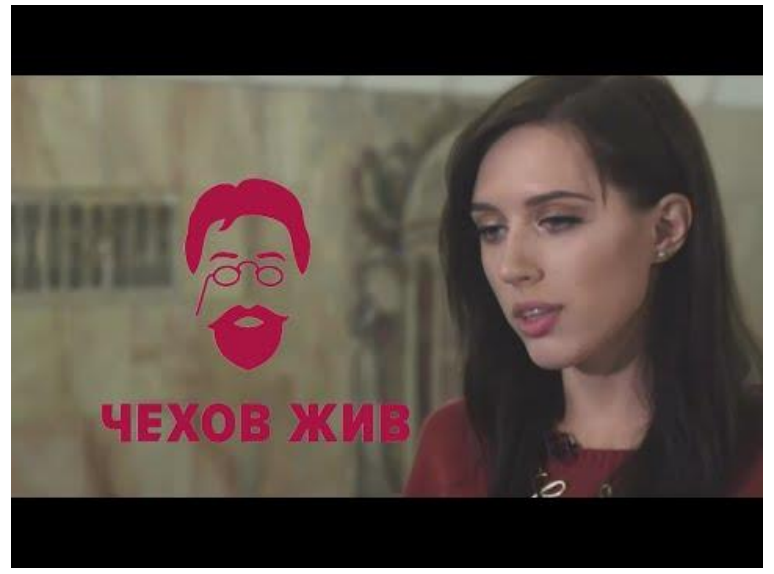

One more touching social project created by Google is dedicated to the Second World War; such projects tend to evoke a wide emotional response.

At this time, celebrities, including video bloggers, were reading soldiers' letters. This project was called "A Living Memory". Its aim was to attract the younger generation's attention to the tragedy of the Great Patriotic War. The organizers' idea is quite understandable; by involving top bloggers, they managed to widen the project's target audience. One of the content-makers was the most popular ladyblogger Kate Clapp.

In April 2017, Google implemented another social project called "YouTube Against Bullying".

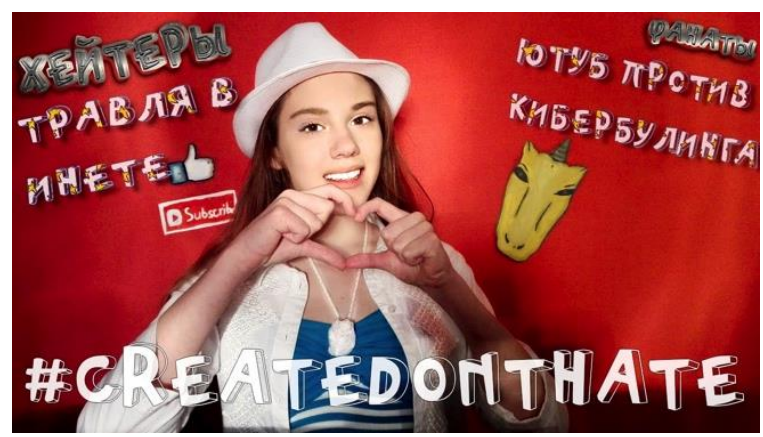

Cyberbullying, electronic bullying, and online social cruelty make up a separate type of bullying defined as premeditative aggressive actions performed by a group or an individual systemically over a certain period of time using electronic communication means and levelled at the victims who cannot defend themselves easily [9].

Cyberbullying includes usage of email, instant messages, web pages, blogs, forums, chat rooms, MMS and text messages, online games, and other elements of IT communication [10].

According to Microsoft, in 2012 about a half of children aged 8-17 admitted being bullied. Among 25 countries where cyberbullying is common, Russia ranks the top five [11].

Bloggers know about cyberbullying thanks to their own experience - quite often, they become victims of cyberbullying and hating on the Internet.

That is why Google chose Maryana Ro and Kate Clapp - two top bloggers with a million of subscribers - to be its ambassadors. They made two videos for the official Google Russia YouTube channel, where they shared their experience of confronting cyberbullying. At the end of the video, these bloggers encourage the viewers to make their own videos with a hashtag \#CreateDontHate and use it in a search for an advice.

There is an example of one of the videos with Maryana Ro:

"Cheers, mates. My name is Maryana and this is not my channel. I want to talk about cyberbullying. Have I faced hating and how do I fight it? I believe that the best thing we can do against cyberbullying is to ignore it. Every time, when people are writing angry comments, pranking me, or trying to mock me, I ignore them, because it is the right thing to do. I decided to become an ambassador of YouTube against Cyberbullying because I know how difficult it is to fight hate. Let's fight cyberbullying together. Make videos, use this hashtag and I'm sure that we will make the Internet a little bit kinder".

In her video, Maryana uses a question-answering form of verbal communication. She asks a question and then answers it herself. Besides, Maryana uses stylistically marked words and slang. Cyberbullying is most common among the younger audiences, especially children. Their psychical state is usually very vulnerable, in this age they are prone to different types of manipulative influences. Stylistics of this advertising campaign coincides with speech peculiarities of the target audience. The speaker uses informal words "hating", "to prank", "to mock". She also uses an infinitive of the verb "to make".

Non-verbal elements, such as \#CreateDontHate hashtag, blogger dressed in youngsters' style, dynamic cutting, internoises, etc., are aimed at attracting the young audience. 


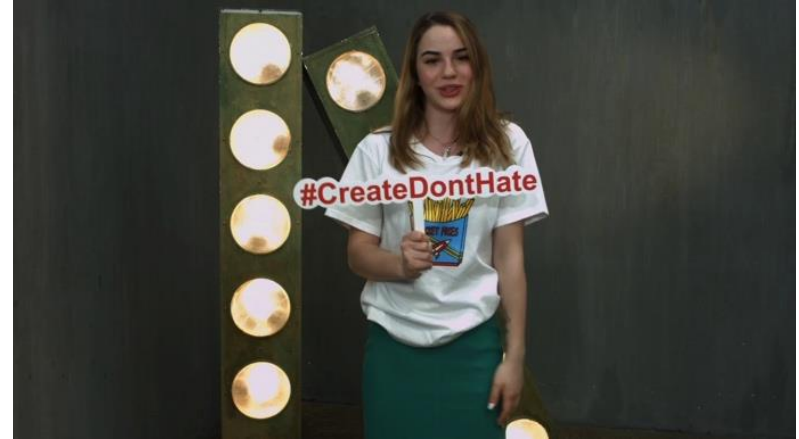

According to statistics, video blogging is becoming more effective tool for influencing the audience. Different brands can feel this trend and attract bloggers to their social and commercial projects.

Nike, a world-leading manufacturer of sports outfits, is a socially responsible company. This brand supports athletes and sports teams all around the globe, organizes public workouts in the largest cities of the world, thus promoting its brand through people's love for a healthy lifestyle.

In 2017, Nike created an advertising video called "What Are Our Girls Made Of?". Famous womenathletes Adelina Sotnikova (figure skating), Anastasiya Yankova (Mixed Martial Arts), Olga Kuraeva (ballerina), Irina Gorbatcheva (actress), Katya Shengeliya (skateboarding), Kristina Sivkova (light athletics), Anastasiya Kotelnikova (Nike+ Training Club coach), Kseniya Lazareva (soccer) took part in this project.

The video starts with a canonic children's song, but in a few moments the situation changes, as well as woman's role in the society, a woman is not weak, because "our girls are made of aspiration, devotion, and fights". This verbal part is supported by nonverbal elements; famous athletes, who have proved their strength, appear on the screen.

To widen the advertising campaign's audience Nike started its collaboration with Maria Novosad, a famous Russian lifestyle-blogger with 540 thousand followers, $93 \%$ of whom are women.

In 2 days after Nike's video broadcast, Maria made a video and uploaded it to her YouTube channel. In this video, she shared her experience of fighting the lack of self-confidence and interviewed some women that participated in filming Nike's video.

"Russian girls often become victims of public opinion. We often don't do what we want because we don't know what people would say. These stereotypes make you work twice and be ready both morally and physically. One the one hand, it makes your way harder; on the other hand, it makes your character. You should be brave to be yourself... [from the interview with the participants of Nike's video] ... All these girls have united thanks to one thing - they do what they like. Without thinking about other people's opinions, they keep on setting records and breaking stereotypes; they are the ones who change the culture of sport. We are the ones who change the culture of sport. Let us show together who we really are and what we are made of. I'm made of selfconfidence. What about you?"

This text includes manipulative tools of lexical repetition; with their help, the speaker can form and set a desired behavioural pattern: "be brave", "be yourself", "they are the ones who change the culture of sport", "we are the ones who change the culture of sport". The author also uses an inclusive pronoun "we". This "we" pronoun often becomes a means for public opinion manipulations. This pronoun turns into an ideologeme of unity: "we are the ones who change the culture of sport", "we often don't do what we want", "who we are", "what we are made of". In the end, the speaker uses a personal pronoun "I", which is used for appealing to the personal experience: "I'm made of self-confidence".

This pronoun "I" is to stimulate Maria Novosad's followers to make a change. That is why the author uses an interrogative construction urging to perform some action: "What about you?" The imperative form "let's" contributes to manipulative effect and presses to act. The speaker also uses the tools of dialogization in the form of addressing. This allows the addressee to piece herself on with the audience, to build trust, and to blend in.

\section{Conclusions}

Involvement of bloggers - new celebrities - into social projects is an effective way to enlarge the project's target audience, to position it on the Internet, to receive feedback from the blogger's audience; all these elements contribute to successful communication of the social project.

Being the opinion leaders for most of the young people bloggers can form their audiences' opinions and manipulate them; these audiences may include up to several million people.

New technologies make some corrections in a modern person's life - he or she may have an unlimited access to different information resources, social networks, blogs, etc.; these technologies stipulate development of integrated communications, help to create new promotion tactics and strategies, and make use of creative potential.

Social communications often use emotional argumentation supported by rational motives; in other words, there emerge a symbiosis that helps to influence the addressee of an advertising text more effectively.

Social advertising also uses modern mechanisms of influencing the target audiences because its main aim is to be heard and to promote a definite model of life. That is why bloggers who have a reputation potential are engaged in the social communication.

The reported study was funded by RFBR and Government of the Omsk region according to research project № 17-1455001.

\section{References}


1. N. Hollis, G. Pinkcott Marketing in Russia and Abroad 6, 109-113 (2013)

2. I.M. Dinner, H.J. Van Heerde, S.A. Neslin, Journal of Marketing Research 51 (5), 527-545 (2014)

3. J. Gong, M. D. Smith, R. Telang, Journal of Retailing 91 (2), 343-357 (2015).

4. L. Huang, X. Lu, S. Ba Information \& Management 53 (2), 265-278 (2016)

5. E. Neufeld, Journal of Advertising Research 57 (1), 109-117 (2017)

6. W. Gao, Y. Tian, T. Huang, Q. Yang, ACM Computing Surveys 42 (4), Article 15 (2010).

7. D.Z. Bayazit, B. Durmus, F. Yildirim Online Academic Journal of Information Technology http://www.ajit-

e.org $/$ ?menu $=$ pages $\& p=$ details of article $\& i d=24$ $\underline{2}(2017)$

8. C. Chapple, F. Cownie Journal of Promotional Communications 5 (2), 110-136 (2017)

9. P.K. Smith, J. Mahdavi, M. Carvalho, S. Fisher, S. Russel, N. Tippett, Journal of Child and Psychiatry 49, 376-385 (2008)

10. R.M. Kowalski, S.P. Limber, P.W. Agatston Cyberbullying: Bullying in the digital age (Chichester: Wiley-Blackwell, 2011).

11. Bullying in Russia. https://nobullying.com/bullying-in-russia/ 